\title{
Erweiterung des Treuhandpartnernetzes in Biel
}

FMH Consulting Services bietet seit dem 1. März 2009 mit der WM Treuhand AG, Biel, einen weiteren kompetenten Treuhandpartner in ihrem Netz an.

Stefan und Andrea Ryser führen die Finanzplanungs-, Steuerberatungs- und Treuhandunternehmung in Biel mit ihrem 6köpfigen Team. Stefan Ryser ist bereits seit Jahren mit der SOLOBROKE AG in Solothurn Vertrauenspartner FMH Insurance Services. Er verfügt über eine 30jährige Erfahrung in der Vorsorge- und Finanzplanung sowie in der Treuhand- und Steuerberatung für eine Vielzahl von Arztund Zahnarztpraxen sowie für KMU. Die Mitarbeitenden verfügen über eine Mischung aus grosser Erfahrung und jugendlicher Innovationsfreudigkeit. Das Dienstleistungsangebot beinhaltet die Auseinandersetzung mit allen betriebswirtschaftlichen und finanziellen Fragen. WM Treuhand AG als Vertrauenspartner FMH Treuhand Services zusammen mit SOLOBROKE AG als Vertrauenspartner FMH Insurance Services, ist gleichbedeutend mit «alles aus einer unabhängigen Hand in Geldfragen»!

Mit der WM Treuhand AG können Sie für Ihre Arztpraxis auf eine persönliche, kompetente und umfassende Unterstützung sowie Beratung zählen.

Dienstleistungsangebot der WM Treuhand AG:

- Beratung bei Praxiseröffnung, -übergaben und -übernahmen

- Beratung bei Umstrukturierung oder Nachfolgeplanung

- Umfassende Steuer- und Abschlussberatung

- Führen der Finanzbuchhaltung

- Lohnbuchhaltung inkl. Sozialversicherungsabrechnungen und Lohnausweise

- Erstellen von Budgets, Liquiditäts-, Finanz- und Businessplänen

- Nachlassplanung und Willensvollstreckung

- Begleitung bei Neu- und Umfinanzierungen

Die massgeschneiderten Lösungen werden zu marktgerechten Konditionen angeboten.

Die Hauptbüros befinden sich bei der Westumfahrung der Stadt Solothurn mit optimalem Zufahrtsweg und genügend Kundenparkplätzen. Die Niederlassung in Biel befindet sich an der Neuengasse 5.

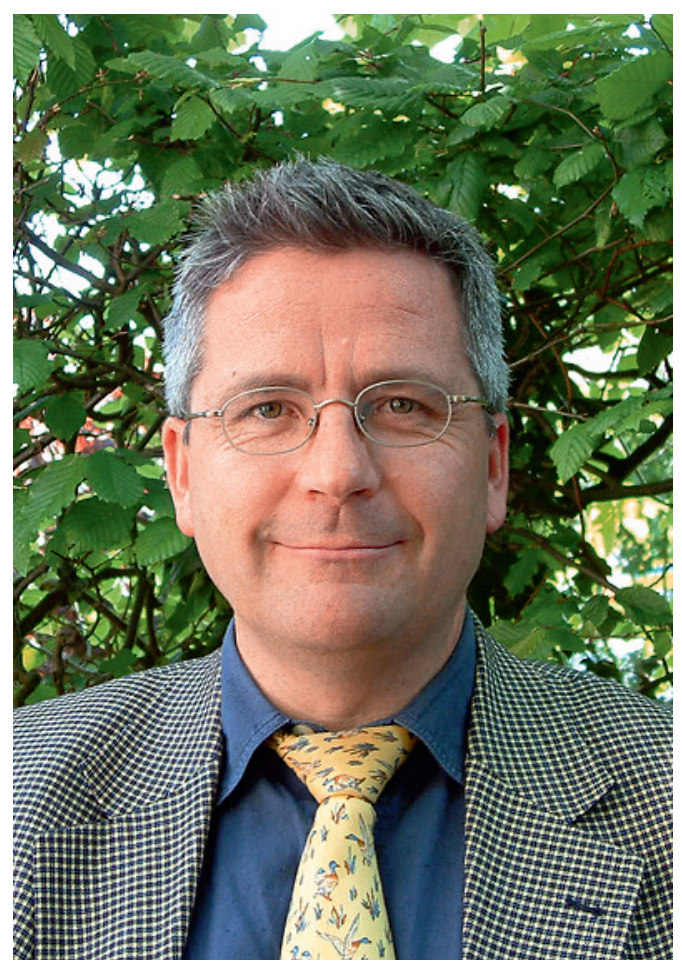

Auf die Kontaktnahme oder Ihren Anruf freut sich:

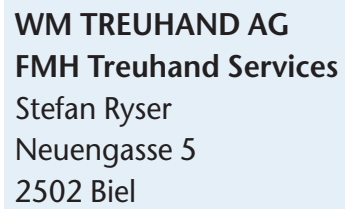

\section{SOLOBROKE AG}

\section{FMH Insurance Services}

Stefan Ryser

Grabackerstrasse 6

4502 Solothurn

Tel. 0326223213 - Fax 0326223215

stefan.ryser@fmhinsurance.ch

www.fmhinsurance.ch 